\title{
Possible Realization of Near Optimum Efficiency from n-Si-Ge/p-Ge-Si DDR Hetero Structure IMPATT Diode
}

\author{
P. R. Tripathy ${ }^{1, *}$, M. Mukherjee ${ }^{2}$, S. P. Pati ${ }^{3}$ \\ ${ }^{1}$ Department of Electronics and Telecommunication Engineering, Purushottam Institute of Engineering and Technology, Rourkela, Odisha, \\ 770034, India \\ ${ }^{2}$ CMSDS, Institute of Radio Physics and Electronics, Calcutta University, Kolkata, 700009, India \\ ${ }^{3}$ National Institute of Science and Technology, Pelur Hills, Berhampur, Odisha, India
}

\begin{abstract}
Avalanche breakdown in a p-n junction can generate rf negative resistance due to twin delay mechanism (Avalanche Delay associated with growth of charge bump and transit time delay caused due to time elapsed for the grown charge bump drifting through the depletion zone) leading to generation of high frequency power in IMPATT mode. With the advancement of device technology and with the motive of furtherance of device performance, replacement of homo junction of single elemental semiconductor with hetero junction, hetero structure junctions from lattice matched pair of elemental semiconductors is now being explored as supported by recent reports. The introduction of an n-Ge and p-Ge impurity bumps on either side of junction interface of a Si p-n junction, results in the formation of a n-Si-Ge/p-Ge-Si hetero structure p-n junction. The analysis of such hetero structure Impatt diode for generation of micro/mm-wave power at designed atmospheric window frequencies of 15 and $94 \mathrm{GHz}$ becomes the scope of the study of this paper. The results are computed through three tier sophisticated computer algorithm indicate efficiency enhancement in case of proposed hetero structure to nearly $29 \%$ (at $\mathrm{X}$-band) as against only $14 \%$ for the corresponding the homo junction diodes associated with increase of diode negative conductance by nearly two fold which in turn could enhance the rf power delivery from the hetero structure diode by many fold. Presence of low BG Ge near high field junction interface and its order high carrier ionization rate (compared to $\mathrm{Si}$ ) localizes the avalanche zone to below $10 \%$ of the depletion zone and thereby pushes the device efficiency and value of negative conductance. However the performance of complementary n-Ge-Si/p-Si-Ge hetero structure remains close to Si or Ge homo junction. The results are highly encouraging which may make Si-Ge-Si Hetero Structure Diode as a prospective microwave generator.
\end{abstract}

Keywords Hetero Structure, DDR, Germanium, Impact Ionization, RF Power, Silicon

\section{Introduction}

Impatt (Impact Avalanche Transit Time) device is a class of rf negative resistance power generator which can cover frequencies from X-band to sub-mm-wave band (10-5000 $\mathrm{GHz}$ ). Any form of junction fabricated from any semiconductor can operate in Impatt mode. Advance research work is being carried out round the globe with the objective of realizing high power at high efficiency and with low noise even at $\mathrm{mm}$ - and sub-mm-wave frequencies[1]. With the advancement of device technology and with the motive of furtherance of device if performance, possible replacement of homo junction of single elemental semiconductor with hetero junction or hetero structure junctions from lattice matched pair of elemental semiconductors is being explored as supported by recent reports[2-6]. Si and Ge are two

* Corresponding author:

pravashrt76@yahoo.co.in (P. R. Tripathy)

Published online at http://journal.sapub.org/ijme

Copyright (C) 2012 Scientific \& Academic Publishing. All Rights Reserved conventional group IV semiconductors having tolerable lattice mismatch. Homo junctions from $\mathrm{Si}$ and Ge have become a reality in producing Impatt Power since decades. Hetero junctions from $\mathrm{Si}$ and $\mathrm{Ge}$ for other purposes have already been reported[7].

The authors have studied a new form of junction in the form of $\mathrm{n}-\mathrm{Si}-\mathrm{Ge} / \mathrm{p}-\mathrm{Ge}-\mathrm{Si}$ hetero structure junction when both the $\mathrm{p}$ - and $\mathrm{n}$ - layers contain two materials. The band gap of $\mathrm{Ge}$ is $0.66 \mathrm{eV}$ where as for $\mathrm{Si}$, it is $1.12 \mathrm{eV}$. The carrier ionization rate causing avalanche breakdown remains high for low BG semiconductors. In fact the carrier ionization rate for Ge is higher by an order of magnitude compared to that for $\mathrm{Si}$ at the same magnitude of electric field. The order gap in values of carrier ionization rate between $\mathrm{Ge}$ and $\mathrm{Si}$ further widens if Ge is placed in high field zone close to junction and Si placed away from junction. With this idea in mind, the authors proposed Si-Ge-Si hetero structure junction of the form $\mathrm{n}-\mathrm{Si}-\mathrm{Ge} / \mathrm{p}-\mathrm{Ge}-\mathrm{Si}$ when Ge impurity bumps are introduced near the junction interface on either sides of conventional $\mathrm{Si}$ homo junction leading to above referred hetero structure junction. The high values of electron and hole 
ionization rate of $\mathrm{Ge}$ in the high field zone near junction plane, thins the avalanche zone to less than $10 \%(3 \%$ in $\mathrm{X}$-band) of the depletion zone on either side of the junction. This phenomenon makes this structure creditable as both the efficiency and diode negative conductance would be pushed to sufficiently high values as compared to both $\mathrm{Si}$ and $\mathrm{Ge}$ homo junctions. The authors have analysed the new diode structure following a sophisticated three tier computer algorithm. The diode has been designed and optimized for atmospheric window frequencies in X-band $(15 \mathrm{GHz})$ and mm-wave band $(94 \mathrm{GHz})$. The results observed are quite interesting indicating this device to be promising candidate for high power generation with high efficiency. The efficiency of this new proposed diode mounts to near optimum value of $29 \%$ for the X-band hetero structure diode as against $12-14 \%$ for homo junctions together with the diode negative conductance being doubled for the hetero structure. These characteristics would help in pushing the rf power delivery from the diode. Further, since the avalanching process is augmented and ionizing layer thinned down drastically, the avalanche noise from the hetero structure may remain quite low.

\section{Computer Simulation Method}

The typical general Impatt diode structure is shown in figure 1 for both the frequencies of design. The minority carriers say holes, under the influence of reverse breakdown voltage (field) crosses from $\mathrm{n}$ side to $\mathrm{p}$ side, passing through the high field zone around the junction. The hole charge concentration grows due to impact avalanche ionization process, thereby the reverse saturation hole current $J_{p s}$ at $n$ side edge grows to $J_{p}$ on the $p$ side extreme. Similarly the minority electron moves from $\mathrm{p}$-side to n-side growing from $J_{n s}$ to $J_{n}$. The charge growth up to the extent of $95 \%$, takes place within the avalanche region $\left(\mathrm{x}_{\mathrm{A}}\right)$. Then the grown charge drifts through drift region (holes in $\mathrm{d}_{\mathrm{p}}$ ) and (electrons in $d_{n}$ ) with respective saturated carrier drift velocity.
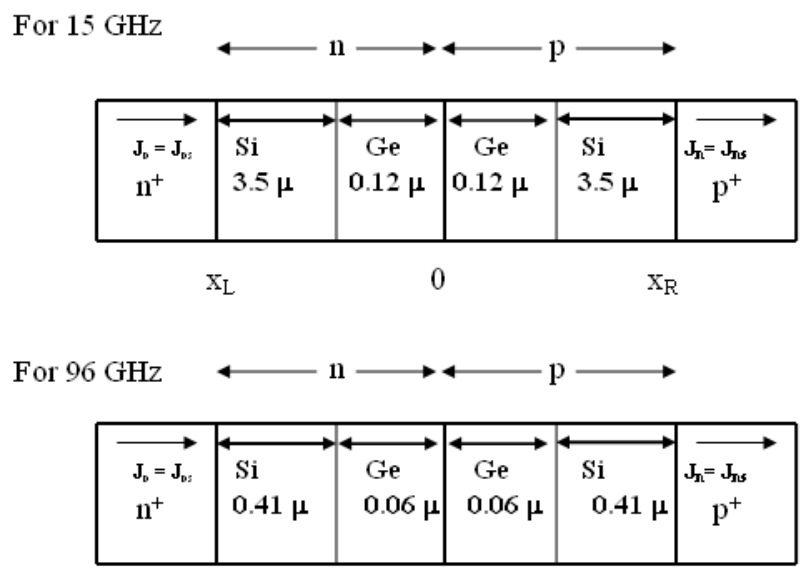

$\mathrm{X}_{\mathrm{L}}$

0

$\mathrm{x}_{\mathrm{R}}$

Figure 1. Schematic diagram of typical double drift n-Si-Ge/p-Ge-Sibased Impatt diode p-n Junction at 15.0 and $96.0 \mathrm{GHz}$

\subsection{Analysis under Static Conditions}

Two separate realistic self-converging iterative computer simulation programs have been framed for DC analysis and small signal analyses. Material parameters like the ionization rate, drift velocities etc., of all the materials have been taken from the recently reported published literature[8-10]. The diode active layer width is divided into large number of space steps of $1 \mathrm{~nm}$ per micron or less. The DC analysis is carried out by solving simultaneously three non-linear device equations namely Poisson's equation, the carrier continuity equation and the space charge equation using a double iterative field maximum initiated simulation program[7] subject to fulfilment of boundary conditions in electric field and carrier currents[11].The basic equations for DC analysis are,

Poisson's equation,

$$
\frac{\partial E}{\partial x}=\frac{q}{\epsilon}\left(\mathrm{N}_{\mathrm{D}}-\mathrm{N}_{\mathrm{A}}+\mathrm{p}-\mathrm{n}\right)
$$

and the current continuity equation is given by,

$$
\frac{1}{q} \frac{\partial J_{p}}{\partial x}=\mathrm{g}=-\frac{1}{q} \frac{\partial J_{n}}{\partial x}
$$

where

$$
\mathrm{g}=\alpha_{\mathrm{n}} \mathrm{n} \mathrm{v}_{\mathrm{n}}+\alpha_{\mathrm{p}} \mathrm{p} \mathrm{v}_{\mathrm{p}}
$$

Taking the drift velocity $\sim$ field variation to be represented by, $\left.v_{\mathrm{n}, \mathrm{p}}=v_{\mathrm{sn}, \mathrm{sp}[} 1-\exp \left(-\mu_{\mathrm{n}, \mathrm{p}} \mathrm{E} / \mathrm{v}_{\mathrm{sn}, \mathrm{sp}}\right)\right]$

Combined space charge equation can be written as,

$$
\begin{aligned}
& \mathrm{q} \frac{\partial(p-n)}{\partial x}=-\mathrm{q}\left(\alpha_{\mathrm{n}}-\alpha_{\mathrm{p}}\right)(\mathrm{p}-\mathrm{n})+\mathrm{J}\left(\frac{\alpha_{n}}{v_{p}}+\frac{\alpha_{p}}{v_{n}}\right)+ \\
& \left\{\frac{J_{p} \mu_{p}}{v_{p}}\left(\frac{1}{v_{s p}}-\frac{1}{v_{p}}\right)-\frac{J_{n} \mu_{n}}{v_{n}}\left(\frac{1}{v_{s n}}-\frac{1}{v_{n}}\right)\right\} \frac{\partial E}{\partial x} \\
& =-\mathrm{q}\left(\alpha_{\mathrm{n}}-\alpha_{\mathrm{p}}\right)(\mathrm{p}-\mathrm{n})+\mathrm{J}\left(\frac{\alpha_{n}}{v_{p}}+\frac{\alpha_{p}}{v_{n}}\right)+\frac{\partial E}{\partial x} \cdot \mathrm{K}
\end{aligned}
$$

Where $\mathrm{K}=\frac{J_{p} \mu_{p}}{v_{p}}\left(\frac{1}{v_{s p}}-\frac{1}{v_{p}}\right)-\frac{J_{n} \mu_{n}}{v_{n}}\left(\frac{1}{v_{s n}}-\frac{1}{v_{n}}\right)$

is regarded as correction factor and can be evaluated from velocity $\sim$ field characteristics in any semiconductor. The equations (1), (2) and (4), which consider only drift current, can be modified to incorporate diffusion and tunnel currents[12]. The dc analysis gives drift voltage drop $\left(\mathrm{V}_{\mathrm{D}}\right)$, normalized avalanche zone $\left(\mathrm{x}_{\mathrm{A}} / \mathrm{W}\right)$, breakdown electric field and voltage $\left(E_{m} \& V_{B}\right)$, qualitative value of device efficiency

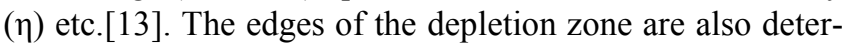
mined accurately from this analysis. The DC electric field profiles, carrier current profiles, breakdown voltage etc. are obtained from this analysis. We have considered a one-dimensional model with doping distributions of the form $\mathrm{n}^{+} \mathrm{npp}^{+}$. The data obtained from the DC analysis are used as input for the high frequency analysis of the diode. The next phase of the computation has been designed for computation of RF properties of the optimized diodes over a wide band of frequencies. Implicit second order device equations on diode resistance and susceptance are framed based on Gummel-Blue approach[14].

\subsection{High Frequency Analysis}

The ac model takes into account the contribution of nega- 
tive resistance from each space point and effectively determines the device performance parameters such as negative conductance $(-G)$, susceptance $(B)$ and negative resistance $\left(-Z_{R}\right)$ of the diode. The variations of these values with frequency are also computed with the help of another double iterative computer program[15]. In the high frequency analysis, it is possible to find out the spatial variation of negative resistance $(\mathrm{R})$ and reactance $(\mathrm{X})$ in the depletion layer which would provide a clear idea regarding intensity of microwave oscillation produced along different region of the diode. The unperturbed diode impedance $\mathrm{Z}_{0}$ (without considering diffusion current) is separated into its real and imaginary components (i.e. $\mathrm{Z}_{0}=\mathrm{R}_{0}+\mathrm{i} \mathrm{X}_{0}$ ) to obtain the second order non-linear implicit differential equation in small signal resistance $\left(\mathrm{R}_{0}\right)$ and reactance $\left(\mathrm{X}_{0}\right)$ as,

$$
\begin{aligned}
& \frac{\partial^{2} R_{0}}{\partial x^{2}}+\left(\alpha_{n}-\alpha_{p}\right) \frac{\partial R_{0}}{\partial x}-\frac{2 r \omega}{-} \frac{\partial X_{0}}{\partial x}+\left[\frac{\omega^{2}}{\overline{-}^{2}}-H(x)\right] R_{0}-\frac{2 \bar{\alpha} \omega}{\bar{v}} X_{0}=\frac{2 \bar{\alpha}}{\bar{v} \varepsilon} \\
& \frac{\partial^{2} X_{0}}{\partial x^{2}}+\left(\alpha_{n}-\alpha_{p}\right) \frac{\partial X_{0}}{\partial x}+\frac{2 r \omega}{\bar{v}} \frac{\partial R_{0}}{\partial x}+\left[\frac{\omega^{2}}{\overline{-}^{2}}-H(x)\right] X_{0}+\frac{2 \alpha \omega}{\bar{v}} R_{0}=-\frac{\omega}{\bar{v}^{2}}
\end{aligned}
$$

With $\mathrm{H}(\mathrm{x})=$

$$
\frac{2 j}{-} \frac{\partial \bar{\alpha}}{\partial E}+\frac{q r_{+}}{-} \frac{\partial}{\partial E}\left[g_{T n}(x)+g_{T p}\left(x^{\prime}\right)\right]+\frac{\partial}{\partial E}\left(\alpha_{p}-\alpha_{n}\right) \frac{\partial E_{m}}{\partial x}
$$

The equations (5) and (6) are solved simultaneously by modified Runge-Kutta method[16]. Finally the small signal diode resistance $(\mathrm{R})$ and reactance $(\mathrm{X})$ due to drift, diffusion and tunnel currents are obtained from the expression including perturbation part,

$$
\mathrm{R}=\mathrm{R}_{0}+\sum_{k} R_{k} \text { and } \mathrm{X}=\mathrm{X}_{0}+\sum_{k} X_{k}
$$

The integrated values of resistance and reactance give $Z_{R}$ and $\mathrm{Z}_{\mathrm{X}}$ using the relation,

$$
Z_{R}=\int_{0}^{w} R(x) d x \text { and } Z_{x}=\int_{0}^{w} X(x) d x
$$

Using the values of $Z_{R}$ and $Z_{X}$, the diode conductance $(G)$, susceptance (B) and the quality factor (Q) are calculated using the relation

$$
\mathrm{G}=\frac{Z_{R}}{Z_{R}^{2}+Z_{x}^{2}} \quad \mathrm{~B}=\frac{-Z_{x}}{Z_{R}^{2}+Z_{x}^{2}} \text { and } \mathrm{Q}=-\left|\frac{B}{G}\right|
$$

The series positive resistance $\left(\mathrm{R}_{\mathrm{S}}\right)$ of the device, which is one of the important limiting factors responsible for limiting power output and device efficiency, can also is determined. The RF power is estimated from the following[17]:

$$
P_{R F}=\left(V_{B} / 2\right)^{2} \times G_{p} A / 2
$$

where, $\mathrm{V}_{\mathrm{RF}}$ can be approximated as $\mathrm{V}_{\mathrm{B}} / 2$ for $50 \%$ modulation. $G_{p}$ is the device negative conductance at peak frequency. $\mathrm{A}$ is the area of the diode is taken as $10^{-9} \mathrm{~m}^{2}$ for 94 $\mathrm{GHz}$ and $1-5 \times 10^{-8} \mathrm{~m}^{2}$ for $15 \mathrm{GHz}$ as obtained from experimental report. The high frequency analysis also gives the negative resistance distribution, $\mathrm{R}(\mathrm{x})$, profile, along the depletion zone which indicates the intensity of RF oscillation from individual space step. The avalanche phase delay $\left(\theta_{\mathrm{a}}\right)$ and transit phase delay $\left(\theta_{\mathrm{t}}\right)$ can also be obtained from the $\mathrm{R}(\mathrm{x})$ profile. The devices can be subjected to fine structure optimization through variation of diode structural parameters in order to optimize the value of RF negative resistance which can be achieved when the values of $\theta_{\mathrm{a}}$ and $\theta_{\mathrm{t}}$ are close to $\pi / 2$ and the peaks of the $\mathrm{R}(\mathrm{x})$ profile in the drift zones are located close to the centre of the drift zones in both ' $n$ ' and ' $p$ ' regions. The results of $\mathrm{DC}$ and microwave performance analyses for $\mathrm{n}-\mathrm{Si}-\mathrm{Ge} / \mathrm{p}-\mathrm{Ge}-\mathrm{Si}$ hetero structure double drift IMPATT diodes $\left(\mathrm{n}^{+} \mathrm{npp} \mathrm{p}^{+}\right)$have been studied and presented in this paper.

\section{Computer Algorithm for DC and RF Analysis}

Computer solutions become essential for understanding the properties of the devices, as analytical methods are not feasible to provide accurate information regarding the DC and high frequency parameters of these devices as the equations are complicated.

\subsection{Computer Method}

First the value of the field maximum $\mathrm{E}_{0}$ and its location $\mathrm{x}_{0}$ are suitably chosen for the diode. Then the Poisson's equation and the carrier continuity equations are solved simultaneously through numerical approach. The space step width is taken to be very small i.e. of the order of nms (1000 steps per micron). The numerical solution is progressed from the point $\mathrm{x}=\mathrm{x}_{0}$ and moving first towards the right side and then towards left hand side of the field maximum till the field/carrier current boundary conditions are satisfied at $\mathrm{X}=\mathrm{x}_{\mathrm{R}, \mathrm{L}}$. A four track rapidly converging logic is framed to get the boundary condition satisfied at the edges of the depletion layer. The breakdown characteristics, efficiency are thus obtained from final solution[7].

\subsection{RF Analysis}

Table 1. Physical and Material parameters of $\mathrm{Ge}$ and $\mathrm{Si}$

\begin{tabular}{|c|c|c|}
\hline Property & $\mathrm{Ge}$ & $\mathrm{Si}$ \\
\hline $\begin{array}{c}\text { Ionization coefficient of electrons at low } \\
\text { fields, } \mathrm{A}_{\mathrm{n}}\left(10^{8} \mathrm{~m}^{-1}\right)\end{array}$ & 15.5 & 0.62 \\
\hline $\begin{array}{c}\text { Ionization coefficient of electrons at low } \\
\text { fields, } \mathrm{B}_{\mathrm{n}}\left(10^{8} \mathrm{Vm}^{-1}\right)\end{array}$ & 1.56 & 1.31 \\
\hline $\begin{array}{c}\text { Ionization coefficient of holes at low fields, } \mathrm{A}_{\mathrm{p}} \\
\left(10^{8} \mathrm{~m}^{-1}\right)\end{array}$ & 1.0 & 2.0 \\
\hline $\begin{array}{c}\text { Ionization coefficient of holes at low fields, } \mathrm{B}_{\mathrm{p}} \\
\left(10^{8} \mathrm{Vm}^{-1}\right)\end{array}$ & 1.28 & 2.17 \\
\hline $\begin{array}{c}\text { Saturation drift velocity of Electron, } \mathrm{V}_{\mathrm{sn}}\left(\times 10^{5}\right. \\
\mathrm{m} / \mathrm{s})\end{array}$ & 6.0 & 7.3 \\
\hline $\begin{array}{c}\text { Saturation drift velocity of holes, } \mathrm{V}_{\mathrm{sp}}\left(\times 10^{5}\right. \\
\mathrm{m} / \mathrm{s})\end{array}$ & 8.0 & 6.7 \\
\hline Electron Mobility, $\mu_{\mathrm{n}}\left(\mathrm{m}^{2} \mathrm{~V}^{-1} \mathrm{~S}^{1}\right)$ & 0.039 & 0.014 \\
\hline Hole Mobility, $\mu_{\mathrm{p}}\left(\mathrm{m}^{2} \mathrm{~V}^{-1} \mathrm{~S}^{-1}\right)$ & 0.019 & 0.045 \\
\hline Permitivity, $\varepsilon\left(10^{-11} \mathrm{~F} / \mathrm{m}\right)$ & 14.1 & 10.1 \\
\hline Band Gap, $\mathrm{E}_{\mathrm{g}}(\mathrm{eV})$ & 0.67 & 1.12 \\
\hline
\end{tabular}

A fast converging and double iterative computer program is framed, which performs iteration over the initial values of 
$\mathrm{R}_{0}$ and $\mathrm{X}_{0}$ at the left hand edge $\left(\mathrm{x}=\mathrm{x}_{\mathrm{L}}\right)$ till the boundary condition is satisfied at the other edge $\left(\mathrm{x}=\mathrm{x}_{\mathrm{R}}\right)$. The iteration over initial choice of $\mathrm{R}_{0}$ and $\mathrm{X}_{0}$ at the beginning of each iteration involves a four-way adjustment possibility for which logic is framed to guide the iteration to the converging track. The final solutions at various frequencies for a particular diode have been studied to assess the RF properties. The high frequency analysis gives the bandwidth (BW), peak frequency $\left(f_{p}\right)$, negative device conductance $\left(G_{p}\right)$, negative resistance $\left(Z_{p}\right)$, negative resistance profile, avalanche phase delay and other related parameters. The bandwidth for RF generation, the negative conductance, positive series resistance, and avalanche phase delay etc. also can be calculated from the final solution[16]. Further the negative series resistance generation profile across the depletion zone can be obtained for the analysis to give some interesting features.

\section{Results and Discussions}

$\mathrm{Si} / \mathrm{Ge}$ hetero diode structure having the form $\mathrm{n}$-Si$\mathrm{Ge} / \mathrm{p}-\mathrm{Ge}-\mathrm{Si}$ has been designed and optimized for frequencies of operation around 15 and $96 \mathrm{GHz}$. The materials parameters of both the materials are taken from recent experimental reports[8-10] are shown in Table 1 . The electron/hole ionization rate $(\alpha, \beta)$ are obtained using exponential equations of the form,

$$
\alpha, \beta=A_{n, p} \exp \left(b_{n, p} / E\right)^{m}, m=1.0 \text { for Si and Ge }
$$

The structural and design parameter for the diode are presented in table 2 . The realistic doping profile across the junction is considered through use of an appropriate exponential function. A thin and highly doped Ge layer of width $120 \mathrm{~nm}$ and doping, $1 \times 10^{23} / \mathrm{m}^{3}$, (as compared to Si layer, width $=3.5$ micron, doping $=3 \times 10^{21} / \mathrm{m}^{3}$ ) is considered near the junction plane. The presence of highly doped Ge layer pushes the breakdown electric field maximum value $\left(3.17 \times 10^{7} \mathrm{~V} / \mathrm{m}\right)$.

Table 2. Structural parameters of $n-S i-G e / p-G e-S i$ Hetero-structure based IMPATTs

\begin{tabular}{|c|c|c|c|c|c|}
\hline $\begin{array}{c}\text { Design Fre- } \\
\text { quency } \\
\text { Band }\end{array}$ & $\begin{array}{c}\text { Structural } \\
\text { parameters }\end{array}$ & $\mathrm{n}-\mathrm{Si}$ & $\mathrm{n}-\mathrm{Ge}$ & $\mathrm{p}-\mathrm{Ge}$ & $\mathrm{p}-\mathrm{Si}$ \\
\hline \multirow{2}{*}{$15 \mathrm{GHz}$} & $\mathrm{N}_{\mathrm{D}} \times\left(10^{21} \mathrm{~m}^{-3}\right)$ & 3.0 & 100 & 100 & 3.0 \\
\cline { 2 - 6 } & Width (micron) & 3.5 & 0.12 & 0.12 & 3.5 \\
\hline \multirow{2}{*}{$96 \mathrm{GHz}$} & $\mathrm{N}_{\mathrm{D}} \times\left(10^{21} \mathrm{~m}^{-3}\right)$ & 38.0 & 200 & 200 & 38.0 \\
\cline { 2 - 6 } & Width (micron) & 0.41 & 0.06 & 0.06 & 0.41 \\
\hline
\end{tabular}

Table 3. DC and Microwave properties of Hetero-structure DDRs

\begin{tabular}{|c|c|c|}
\hline $\begin{array}{c}\text { Frequency } \rightarrow \\
\text { Properties } \downarrow\end{array}$ & $15 \mathrm{GHz}$ & $96 \mathrm{GHz}$ \\
\hline Electric Field, $\mathrm{E}_{\mathrm{m}}\left(\times 10^{7} \mathrm{~V} / \mathrm{m}\right)$ & 3.17 & 3.586 \\
\hline Breakdown Voltage, $\mathrm{V}_{\mathrm{B}}(\mathrm{V})$ & 85.9 & 13.2 \\
\hline $\mathrm{X}_{\mathrm{A}} / \mathrm{W}(\%)$ & 3.34 & 10.7 \\
\hline Efficiency, $\eta(\%)$ & 28.9 & 24.1 \\
\hline Peak Negative Conductance, $-\mathrm{G}_{\mathrm{p}}\left(\mathrm{S} / \mathrm{m}^{2}\right)$ & $6.99 \times 10^{5}$ & $5.00 \times 10^{7}$ \\
\hline Negative Resistance- $\mathrm{Z}_{\mathrm{R}}\left(\Omega . \mathrm{m}^{2}\right)$ & $3.29 \times 10^{-5}$ & $6.18 \times 10^{-9}$ \\
\hline RF Power $\mathrm{P}_{\mathrm{RF}}($ Watt $)$ & 6.447 & 1.089 \\
\hline
\end{tabular}

Table 4. DC and Microwave properties of $\mathrm{Si}$ and Ge Homo-structure DDRs at $94 \mathrm{GHz}$

\begin{tabular}{|c|c|c|}
\hline Diode Parameter & $\mathrm{Ge}$ & $\mathrm{Si}$ \\
\hline Maximum Electric field, $\mathrm{E}_{\max }\left(\times 10^{7} \mathrm{~V} / \mathrm{m}\right)$ & 3.07 & 6.5 \\
\hline Breakdown voltage $\mathrm{V}_{\mathrm{B}}(\mathrm{V})$ & 9.88 & 18.6 \\
\hline Efficiency $\eta(\%)$ & 12.3 & 9.43 \\
\hline $\mathrm{X}_{\mathrm{A}} / \mathrm{W}(\%)$ & 47.0 & 48.3 \\
\hline Peak operating frequency, $\mathrm{f}_{\mathrm{p}}(\mathrm{GHz})$ & 94.0 & 94.0 \\
\hline Negative Conductance, $-\mathrm{G}_{0}\left(\times 10^{6} \mathrm{~S} / \mathrm{m}^{2}\right)$ & 19.5 & 27.6 \\
\hline Negative resistance, $-\mathrm{Z}_{\mathrm{R}}\left(\times 10^{-8} \Omega . \mathrm{m}^{2}\right)$ & 0.103 & 0.40 \\
\hline Positive Resistance, $+\mathrm{R}_{\mathrm{S}}\left(\times 10^{-9} \Omega \mathrm{m}^{2}\right)$ & 0.158 & 0.68 \\
\hline RF Power $\mathrm{P}_{\mathrm{RF}}(\mathrm{Watt})$ & 0.237 & 1.19 \\
\hline
\end{tabular}

The ionization rate in Ge is observed to be higher by an order of magnitude than $\mathrm{Si}$ at the same electric field. The gap in the values of carrier ionization rate in $\mathrm{Si}$ and $\mathrm{Ge}$ further widens as the Ge layer remains near the high field junction plane where as $\mathrm{Si}$ layer is considered away from the junction. The results of dc/RF analyses are shown in Table 3. The avalanche zone in case of $15 \mathrm{GHz}$ hetero structure diode becomes only $3.34 \%$ of the total depletion width (for Si or Ge homo junction it is $47 \%-48 \%$ ). The efficiency of the device has been computed to be very high i.e., $28.9 \%$ as compared to $12-14 \%$ for $\mathrm{Si}$ and Ge homo DDRs. Even for $96 \mathrm{GHz}$ operation, the efficiency for such $\mathrm{Si} / \mathrm{Ge}$ hetero structure DDR becomes $24.1 \%$. The efficiency of Si or Ge homo DDR has been seen to be around 9-12\% and even for Si Low-high-low complicated multilayered diode, it is around $14.1 \%$. If one sees the values of break down voltage, for $\mathrm{Si} / \mathrm{Ge}$ hetero structure diode at $94 \mathrm{GHz}$, it is computed to be $13.2 \mathrm{~V}$ as against only $9.88 \mathrm{~V}$ for Ge diode shown in table 4. However the breakdown voltage has been found to be 18.6 $\mathrm{V}$ for corresponding Si DDR. The value of peak negative conductance $\left(-\mathrm{G}_{\mathrm{P}}\right)$ for the $\mathrm{n}-\mathrm{Si}-\mathrm{Ge} / \mathrm{p}-\mathrm{Ge}-\mathrm{Si}$ DDR structure are $6.99 \times 10^{5} \mathrm{~S} / \mathrm{m}^{2}$ and $5.00 \times 10^{7} \mathrm{~S} / \mathrm{m}^{2}$ at peak frequency 15 and $96 \mathrm{GHz}$ respectively shown in figure 2 . An admittance plot of n-Si-Ge/p-Ge-Si DDR $\left(n^{+} n^{+} p^{+}\right)$IMPATT diode for $15 \mathrm{GHz}$ is shown in figure 3 and for $96 \mathrm{GHz}$ diode shown in figure 4 . The variation of the impedance of the diode with frequency is shown in figure 5. This is also evident that the values of both negative resistance and reactance decreases as the operating frequency increases.

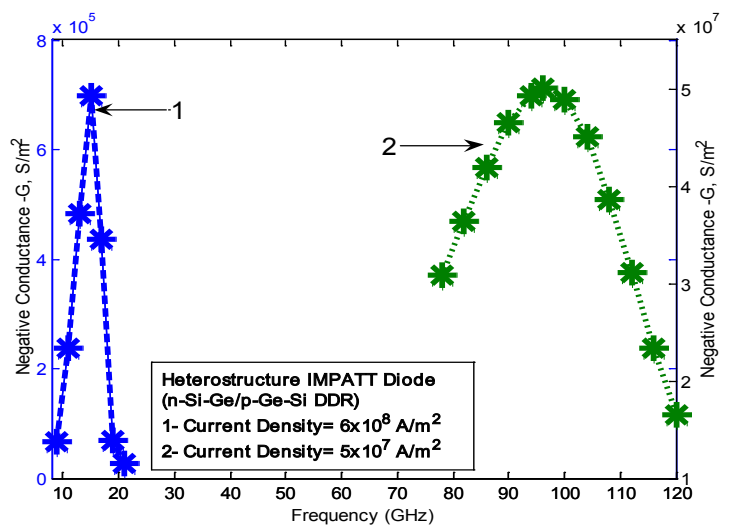

Figure 2. Frequency Vs Negative Conductance for the IMPATT Diode (n-Si-Ge/p-Ge-Si) at both 15 and $96 \mathrm{GHz}$ Peak Frequency 


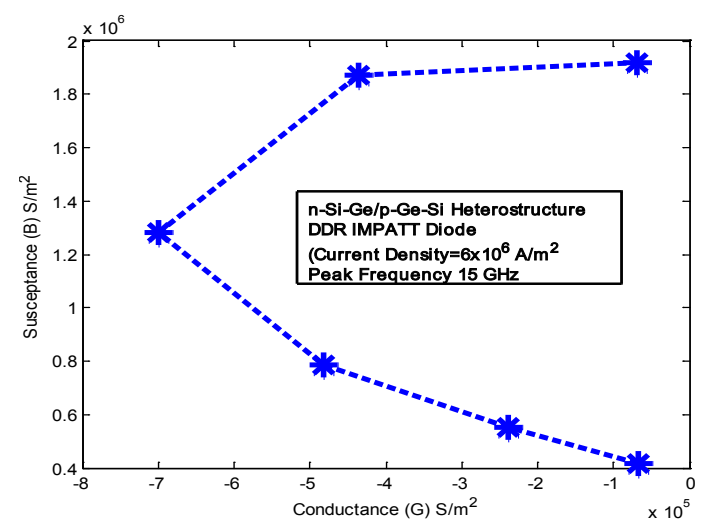

Figure 3. Admittance plot of $n-S i-G e / p-G e-S i$ DDR $\left(n^{+} n p p^{+}\right)$IMPATT diode $($ Peak frequency $=15 \mathrm{GHz})$

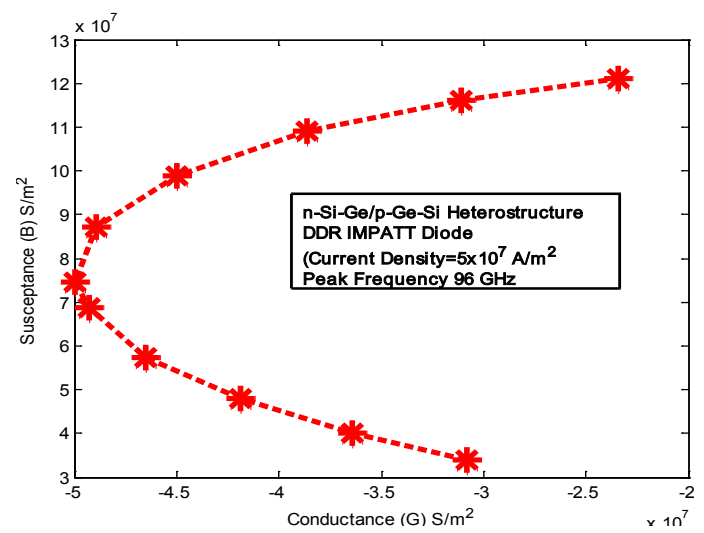

Figure 4. Admittance plot of $n-S i-G e / p-G e-S i$ DDR $\left(n^{+} n p p^{+}\right)$IMPATT diode $($ Peak frequency $=96 \mathrm{GHz})$

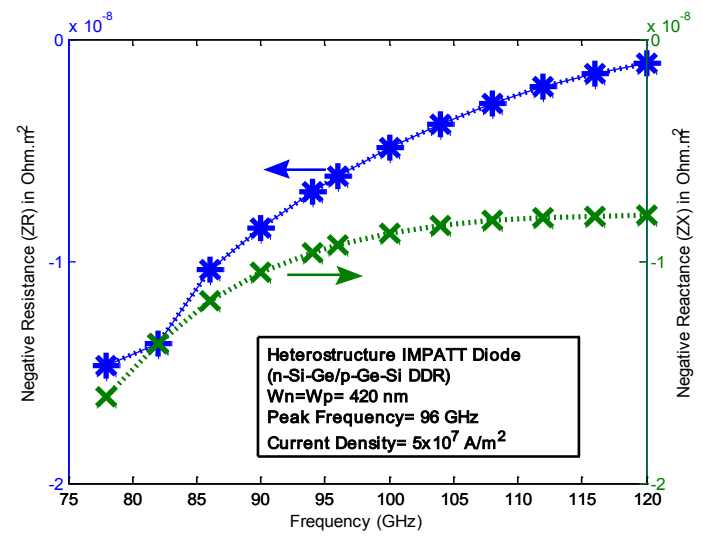

Figure 5. Plots of the variation of impedance of DDR Hetero structure Impatt diode

It has also been observed that the value of negative conductance and negative resistance are higher in case of these hetero structure diodes and these values are sufficiently higher compared to corresponding Ge homo DDR at $94 \mathrm{GHz}$ operation. Thus the high efficiency and high values of negative conductance/negative resistance in case of hetero structure would help in realizing high microwave power. The $\mathrm{RF}$ power of this particular diode is more of about $6.447 \mathrm{~W}$ at $15 \mathrm{GHz}$ and $1.189 \mathrm{~W}$ at operating frequency $96 \mathrm{GHz}$. The inspection of negative resistance profiles (not shown) exhibit the usual double bump character and the magnitudes of the peaks in both the drift zones are observed to be considerably higher for $\mathrm{Si} / \mathrm{Ge} / \mathrm{Si}$ hetero structure as compared to homo junction diodes. The authors have also computed the values of negative conductance at second, third and fourth harmonic frequencies in case of $15 \mathrm{GHz}$ diode. It is interesting to note that the peak value of negative conductance at respective peak frequencies of harmonic bands (at 30, 48 and $68 \mathrm{GHz}$ ) remains almost at same level as of fundamental band. In case of Si or Ge Homo DDR, the values of negative conductance fall appreciably in harmonic peak frequencies. The efficiency of the diode remains the same $(29 \%)$ both in fundamental and harmonic bands. Thus in case of $\mathrm{Si} / \mathrm{Ge} / \mathrm{Si}$ hetero structure, this diode can be operated at higher harmonic frequencies without much loss of microwave power as the negative conductance and efficiency remain at nearly same level even at harmonic peak frequencies. The analysis also has been extended to the complementary hetero structure diode having structure, $\mathrm{n}-\mathrm{Ge}-\mathrm{Si} / \mathrm{p}-\mathrm{Si}-\mathrm{Ge}(\mathrm{Ge} / \mathrm{Si} / \mathrm{Ge})$. The performance of this diode remains close to Si homo junction diode. The presence of low ionising Si near the junction plane causes the loss of advantage of hetero structure.

\section{Conclusions}

Thus the hetero structure diode of the form $\mathrm{n}-\mathrm{Si}-\mathrm{Ge} / \mathrm{p}-\mathrm{Ge}-\mathrm{Si}$ would provide the best $\mathrm{rf}$ performance amongst above cited the homo junction diodes and complementary hetero structure diode.

\section{ACKNOWLEDGEMENTS}

Prof. S. P. Pati wishes to express his sincere thanks to AICTE, New Delhi for grant of Emeritus Fellowship in his favour.

\section{REFERENCES}

[1] R. J. Trew, "High-Frequency Solid-State Electronic Devices", IEEE Trans. on Electron Devices, Vol. 52, No. 5,pp 638-649, 2005.

[2] M. J. Bailey, "Heterojunction IMPATT Diodes", IEEE Trans. Electron Devices, Vol. 39, pp. 1829, 1992.

[3] H. Kanbe, M. Miyaji and T. Ito, "Ge/Si Heterojunction Photodiodes Fabricated by Low Temperature Wafer Bonding", Applied Physics Express 1 (2008) 072301-072303.

[4] Prabhakar Bandaru, Subal Sahni, Eli Yablonovitch, Hyung-Jun Kim and Ya-Hong Xie, " The fabrication of $\mathrm{p}-\mathrm{Ge} / \mathrm{n}-\mathrm{Si}$ photodetectors, compatible with back-end $\mathrm{Si}$ CMOS processing, by low temperature $\left(<400^{\circ} \mathrm{C}\right)$ molecular beam epitaxy and electron-beam evaporation, Mat. Res. Soc. Symp. Proc. 796, V2.8.1-V2.8.6, 2004.

[5] P. R. Bandaru, S. Sahni, E. Yablonovitch, J. Liu, H.-Jun Kim, Y.-H. Xie, "Fabrication and characterization of low temperature $\left(<450^{\circ} \mathrm{C}\right)$ grown $\mathrm{p}-\mathrm{Ge} / \mathrm{n}-\mathrm{Si}$ photodetectors for silicon 
based photonics", Material Science Engineering B 113, pp. 79-84, 2004.

[6] Raid A. Ismail1, Jospen Koshapa, Omar A. Abdulrazaq, "Ge/Si heterojunction photodetector for $1.064 \mu \mathrm{m}$ laser pulses" Internation Journal of Semiconductor Physics, Quantum Electronics \& Optoelectronics, 9, pp. 49-52, 2006.

[7] M. Mukherjee, P. R. Tripathy and S. P. Pati, "Asymmetrical homojunction and heterojunction Transit Time Devices based on $\mathrm{Si} / \mathrm{Ge}$ and $\mathrm{Ge} / \mathrm{Si}$ material systems-A comparative analysis at MM-Wave frequencies", Journal of Semiconductors, Vol. 32, No. 11, pp. 113001-1 to 7, Nov. 2011.

[8] D. J. Massey, J. P. R. David, C. H. Tan, B. K. Nag, G. J. Rees, D. J. Robbins and D. C. Herbert, "Impact ionization in submicron silicon devices", Journal of Applied Physics, Vol. 95, no. 10, pp. 5931-5933, 2004.

[9] Electronic Archive: New Semiconductor Materials, Characteristics and Properties (Online) www.ioffe.ru/SVA/NSM/ Semicond/Si

[10] T. Mikawa, S. Kagawa, T. Kaneda, Y. Toyoma, and O. Mikami, "Crystal orientation dependence of ionization rates in germanium,” Appl. Phys. Lett, vol. 37, no. 4, pp. 387-9, Aug. 1980.

[11] S. K. Dash and S. P. Pati, "Effect of optical radiation on millimeter-wave characteristics and avalanche noise generation in double-drift Impatt diodes based on opto-sensitive semiconductors", Microwave and optical Technology Letter, Vol. 33 no. 4, pp. 295-300, 2002.
[12] S. P Pati and P R Tripathy, Design Consideration for Sub-mm wave Silicon DDRs including drift, diffusion and tunnel currents, Proceeding of XIII International Workshop on the Physics of Semiconductor Devices (IWPSD-2005) 2005; Vol. II pp 822-826.

[13] P. R. Tripathy and S. P. Pati, "Simulation and optimization techniques for millimeter wave Impatt diodes", Proceeding of National Conference on Recent Advances in Communication Technology (NCRACT-2009), pp 67-72, 2009.

[14] H. K. Gummel and J. L. Blue, "A small signal theory of avalanche noise in Impatt diodes”, IEEE ED, Vol-14, pp. 562, 1967.

[15] S. P. Pati, P. R. Tripathy and S. K. Dash, "Avalanche Breakdown Characteristics of Wide Band Gap vis-à-vis Low Band Gap Junctions and High RF Power/Low Noise Generation in ZnS DD IMPATTs", International Journal of Pure and Applied Physics, Vol. 6, Number 2, pp. 229-241, 2010.

[16] M. Mukherjee, P. Tripathy and S. P. Pati, "Effects of mobile space-charge on dynamic characteristics and parasitic resistance of InP Terahertz IMPATT oscillator operating at elevated junction temperature", Archives of Applied Science Research, Vol- 2, issue-3, pp.42-52, 2010.

[17] H. Eisele and G. I. Haddad, Microwave Semiconductor Device Physics, S. M. Sze, Ed. New York: Willey, p. 343, 1997. 